\title{
Structure of Gold-Silver Nanoparticles
}

\author{
Ian J. Godfrey, ${ }^{\dagger, \ddagger \odot}$ Andrew J. Dent, ${ }^{\S}$ Ivan P. Parkin, ${ }^{\dagger}$ Shinya Maenosono, ${ }^{*}+\odot$ and Gopinathan Sankar, ${ }^{*}{ }^{\dagger}$ \\ ${ }^{\dagger}$ Department of Chemistry, University College London, 20 Gordon Street, London WC1H 0AJ, United Kingdom \\ ${ }^{\ddagger}$ School of Materials Science, Japan Advanced Institute of Science and Technology, 1-1 Asahidai, Nomi City, Ishikawa 923-1292, \\ Japan \\ ${ }^{\S}$ Diamond Light Source, Harwell Science and Innovation Campus, Didcot, Oxfordshire OX11 0DE, United Kingdom
}

\section{Supporting Information}

ABSTRACT: Nanoparticles with nominal structures of Au@ Ag (core@shell) and Au@Ag@Au (core@shell@shell) were prepared using the sequential citrate reduction technique and characterized using routine characterization techniques, including transmission electron microscopy. X-ray absorption spectroscopy was then carried out on the samples, and extended X-ray absorption fine structure (EXAFS) analysis was used to determine the structure of the systems. The results of the routine techniques and the X-ray absorption spectroscopy were then compared. EXAFS analysis of the nanoparticles with the Au@Ag structure revealed very limited bimetallic interactions, supporting the assignment of a core@shell structure. EXAFS analysis of the nanoparticles with Au@Ag@Au structure showed an increased proportion of bimetallic interactions. Based on the colloid composition, the other characterization techniques and the chemistry of the system, these nanoparticles were interpreted as having an Au@Au/Ag-alloy structure. The EXAFS analyses corroborated the other characterization techniques and enabled the determination of the average-structure of the entire sample.

\section{INTRODUCTION}

The catalytic properties of both gold ${ }^{1-4}$ and silver ${ }^{5,6}$ nanoparticles have been widely studied and reported in the literature, along with the effect of combining gold with other common catalytic metals. ${ }^{7}$ A range of bimetallic catalysts, ${ }^{7-10}$ not only involving $\mathrm{Au}-\mathrm{Ag}$, but also a variety of other combinations of metals have been investigated in the literature for a wide variety of applications. More recently, research has been carried out to investigate the catalytic activity of gold/ silver bimetallic nanoparticles (alloy and core@shell), whose activity has been found to be structure dependent. ${ }^{8}$ Typically, capping agents are removed and the particles crashed from the colloid before using the particles as catalysts; ${ }^{11,12}$ however, this is not always the case. ${ }^{13,14}$

Multishell bimetallic nanostructures, such as $\mathrm{Au} @ \mathrm{Ag} @ \mathrm{Au}$ (core@shell@shell), are desired for their optical properties. ${ }^{15,16}$ Here, the Ag middle layer displays optimal localized surface plasmon resonance (LSPR) properties with the outer Au shell providing increased stability in biological environments. ${ }^{17}$ In addition, the Au core stabilizes the Ag middle layer against the galvanic replacement reaction; the galvanic replacement would take place if pure $\mathrm{Ag}$ nanoparticles were used as cores and $\mathrm{Au}$ were to be deposited directly onto them. ${ }^{17}$ In some circumstances, gold-silver bimetallic particles have been observed to self-segregate. ${ }^{18,19}$

An important step to experimentally understand the properties of bimetallic systems is to have a good knowledge of the structure of the nanoparticles that have been synthesized.
For the gold/silver system, in particular, this presents substantial challenges due to shortcomings in some of the traditional characterization techniques. For example, both $\mathrm{Au}$ and $\mathrm{Ag}$ have the cubic crystal structures and very similar lattice parameters (Au $4.08 \AA$ vs $\mathrm{Ag} 4.09 \AA$ ), ${ }^{20}$ and thus, it is difficult to distinguish between them by employing $\mathrm{X}$-ray diffraction (XRD; Figure S1, Supporting Information). Consequently, it is also difficult to use XRD to distinguish whether alloy or segregated particles are present in a given sample. Similarly, it is not possible to identify differences in the lattices through high resolution electron microscopy. In transmission electron microscopy, Z-contrast and elemental mapping techniques provide some structural insight, but the presence of the shell will obscure the core, rendering it difficult to conclusively identify the composition of the core. X-ray photoelectron spectroscopy provides information only about the surface of a system, and not the bulk. ${ }^{21}$

$\mathrm{X}$-ray absorption spectroscopy (XAS), on the other hand, is a bulk characterization technique that provides average information about an entire sample, and, in particular, allows for element-specific structure elucidation. This provides a complementary approach to microscopy-based techniques, which typically entail looking at a small number of particles from a given sample.

Received: November 7, 2016

Revised: January 4, 2017

Published: January 4, 2017 
Since X-ray absorption edge energies are element dependent, XAS allows the coordination environment of the gold and silver sites to be probed separately. ${ }^{22}$ In addition, since the backscattering phase-shift depends on the scattering element, the extended X-ray absorption fine structure (EXAFS) is sensitive to different backscattering species, even when they occupy the same lattice site. In such a system, the interference between these phase shifts will manifest itself as a doublet, known as a beat, in the relevant Fourier transform. Thus, EXAFS is sensitive to the presence of alloying, even when the interatomic distances of the alloy and the pure metal are very similar (as in $\mathrm{Au} / \mathrm{Ag}$ systems). ${ }^{23,24}$

Therefore, XAS has been shown to be an effective tool for understanding particle formation, ${ }^{25}$ characterizing bimetallic systems $^{26,27}$ and identifying the coordination environment of metal species. ${ }^{28}$ XAS has also been used to give insight into the electron transfer that is known to occur in the gold-silver system, through analysis of the X-ray absorption near edge structure (XANES) region. ${ }^{29,30}$ Analysis of the EXAFS data allows the quantitative determination of the number and type of each coordinating species around each central (absorbing) element. In the case of an alloy, a large extent of other-metal neighbors will be readily observed; however, for a core-shell system, EXAFS analysis will reveal the dominant interactions as being with the same metal, potentially with some evidence of bimetallic character arising from the interface. ${ }^{19,31}$ The strongest manifestation of this effect will be at the edge of the more dilute element as, in an alloy, this element would have the highest level of bimetallic coordination. By comparing the overall degree of under-coordination at each edge, it is possible to determine which species is dominant at the surface; the presence of species such as oxides is also indicative of this, in certain samples. ${ }^{32}$ Through combining EXAFS results with microscopy measurements, it is possible to fully interpret the structure from the EXAFS data. In this work we aimed to identify the extent of alloy formation using EXAFS. We investigated Au@Ag and Au@Ag@Au as-prepared aqueous colloids produced using the standard citrate reduction,,$^{33-35}$ one of the most widely used synthetic routes to colloidal gold and silver systems. We also used more traditional $\mathrm{Au} / \mathrm{Ag}$ nanoparticle characterization techniques, namely UV-visible spectroscopy (UV-vis), transmission electron microscopy (TEM) and energy dispersive X-ray spectroscopy (EDS), to understand and corroborate the results of the EXAFS analysis. The combined Au L3 and Ag K-edge EXAFS data analyses revealed that the Au@Ag system is predominantly segregated, as expected, but with a small degree of alloying that likely corresponds to the interfacial region. The Au@Ag@Au system showed a greater degree of alloying, producing an $\mathrm{Au} @ \mathrm{Au} / \mathrm{Ag}$ alloy colloid.

Previously, XAS has been used to study supported, ${ }^{12,36}$ sterically stabilized $^{37}$ and concentrated ${ }^{38}$ systems; herein, we present a combined XAS-TEM analysis of dilute, as-prepared gold-silver colloids.

\section{EXPERIMENTAL METHODS}

$\mathrm{HAuCl}_{4}$ (99.999\%), $\mathrm{AgNO}_{3}$ (ACS grade >99.0\%), and trisodium citrate (ACS grade $>99.0 \%$ ) were purchased from Sigma-Aldrich and used as received. $\mathrm{HAuCl}_{4}$, and stock solutions thereof, were stored in the refrigerator. $\mathrm{AgNO}_{3}$, and stock solutions thereof, were stored in opaque containers. Water was purified using either a Purelab Option DV35 (Elga, $15 \mathrm{M} \Omega \cdot \mathrm{cm}$ ) or a Nanopure (Barnstead, $18.2 \mathrm{M} \Omega \cdot \mathrm{cm}$ ).
Gold, silver, and bimetallic colloids were synthesized according to literature procedures. Briefly, gold colloids were prepared by adding trisodium citrate $\left(5.00 \mathrm{~cm}^{3}, 13.5 \mathrm{mM}\right)$ to a boiling solution of $\mathrm{HAuCl}_{4}\left(1.27 \mathrm{~cm}^{3}, 20 \mathrm{mM}\right)$ and water $\left(43.73 \mathrm{~cm}^{3}\right)$ and refluxing for $1 \mathrm{~h}^{39}$ Silver colloids were prepared by adding $\mathrm{AgNO}_{3}\left(0.5 \mathrm{~cm}^{3}, 20 \mathrm{mM}\right)$ to a boiling solution of trisodium citrate $\left(0.2 \mathrm{~cm}^{3}, 40 \mathrm{mM}\right)$ and water $(19.3$ $\mathrm{cm}^{3}$ ) and refluxing for $1 \mathrm{~h} .{ }^{40}$

Core@shell Au@Ag colloids were produced as follows: to a boiling solution of as prepared gold colloid $\left(20 \mathrm{~cm}^{3}\right), \mathrm{AgNO}_{3}$ $\left(3.20 \mathrm{~cm}^{3}, 20 \mathrm{mM}\right)$, trisodium citrate $\left(3.38 \mathrm{~cm}^{3}, 20 \mathrm{mM}\right)$, and water $\left(1.63 \mathrm{~cm}^{3}\right)$ were added and the reaction was stirred and refluxed for 1 h.Au@Ag@Au colloids were prepared by adding $\mathrm{HAuCl}_{4}\left(0.625 \mathrm{~cm}^{3}, 20 \mathrm{mM}\right)$, trisodium citrate $\left(3.38 \mathrm{~cm}^{3}, 20\right.$ $\mathrm{mM})$, and water $\left(1.63 \mathrm{~cm}^{3}\right)$ to a boiling solution of as-prepared $\mathrm{Au} @ \mathrm{Ag}$ colloid $\left(28.21 \mathrm{~cm}^{3}\right)$ and stirring and refluxing for $1 \mathrm{~h}^{17}$ Hereafter, this sample is referred to as Au@Ag@Au

$\mathrm{Au} @ \mathrm{Ag} @ A u$ colloids with reduced Au content in the outer shell were also prepared to investigate the galvanic replacement reaction by measuring particle size. These were prepared in the same fashion as the $\mathrm{Au} @ \mathrm{Ag} @ \mathrm{Au}$ More Au particles but using a reduced amount of $\mathrm{HAuCl}_{4}\left(0.075 \mathrm{~cm}^{3}, 20 \mathrm{mM}\right)$ in the final addition step. Hereafter, this sample is referred to as Au@Ag@ $\mathrm{Au}$ Less Au.

UV-visible spectra of the as prepared colloids in quartz cuvettes were recorded using a Lambda 35 spectrometer (PerkinElmer), a UV-1800 spectrometer (Shimadzu), and a V670 spectrometer (JASCO), diluting as necessary. TEM images were recorded using a JEM-2100 microscope (JEOL), operated at $200 \mathrm{kV}$, and a H-7650 microscope (Hitachi), operated at 100 $\mathrm{kV}$, by loading the as prepared colloid onto a holey carbon grid and allowing the water to evaporate. EDS was carried out using an X-MAX instrument (Oxford Instruments) connected to the JEM-2100 in scanning TEM (STEM) mode and an X-MAX 7235-H instrument (Horiba) connected to the H-7650 microscope. EDS results were analyzed using the Cliff Lorimer technique.

Mean particle sizes and particle size distributions were calculated by measuring the diameter of a minimum of 150 particles (in most cases ca. 300 particles) in ImageJ (v. $1.49 \mathrm{~g})^{41}$ and using the column statistics functions of Origin Pro 9.1 SR3 to generate particle size distribution histograms and statistical data. For the silver colloid, which showed substantial anisotropy, particles were measured along their longest dimension.

XAS data were collected at the BM23 beamline ${ }^{42,43}$ at the European Synchrotron Radiation Facility (ESRF) and the B18 beamline ${ }^{44}$ at the Diamond Light Source. All data was collected in fluorescence mode due to the low sample concentrations. All XAS data was collected on as prepared samples. All data was collected in a bespoke XAS cell (described in ref 45). A schematic of the typical experimental setup is shown in Figure S2 (Supporting Information). Simultaneously with each data collection run, metal foil reference data was recorded.

XAS data were analyzed using the Demeter ${ }^{46}$ and Viper ${ }^{47}$ software packages (v 0.9.20 and v. 1109 respectively). First, multiple scans were merged to improve data quality, using Athena (Demeter), then background removal was carried out using VIPER. Data was fitted to $\mathrm{Au}-\mathrm{Au}$ and $\mathrm{Au}-\mathrm{Ag}$ (Au edge) or $\mathrm{Ag}-\mathrm{Ag}$ and $\mathrm{Ag}-\mathrm{Au}$ (Ag edge) first shell paths, using Artemis (Demeter), and the coordination of each path compared to the composition to identify the presence of alloying. For all samples, the $\mathrm{Au}$ and $\mathrm{Ag}$ data sets were fitted simultaneously. 
For parameters that have the same physical meaning (e.g., Debye-Waller factors and half path lengths for the same path), a shared variable was refined for all applicable paths/edges in a given sample. Further details about the fitting procedure are given in the Supporting Information.

\section{RESULTS AND DISCUSSION}

We will first discuss the UV-visible spectroscopy results, followed by the TEM results. Finally, we will discuss the XAS results, at both the $\mathrm{Au} \mathrm{L} 3$ and $\mathrm{Ag} \mathrm{K}$ edges. We will discuss the EXAFS fitting models chosen at both edges, with respect to the compositions determined by EDS. A fuller analysis of the EDS and high-resolution TEM (HRTEM) data is given in the Supporting Information (SI).

UV-vis spectra of the colloids are shown in Figure 1. These are found to be similar to the previously reported literature

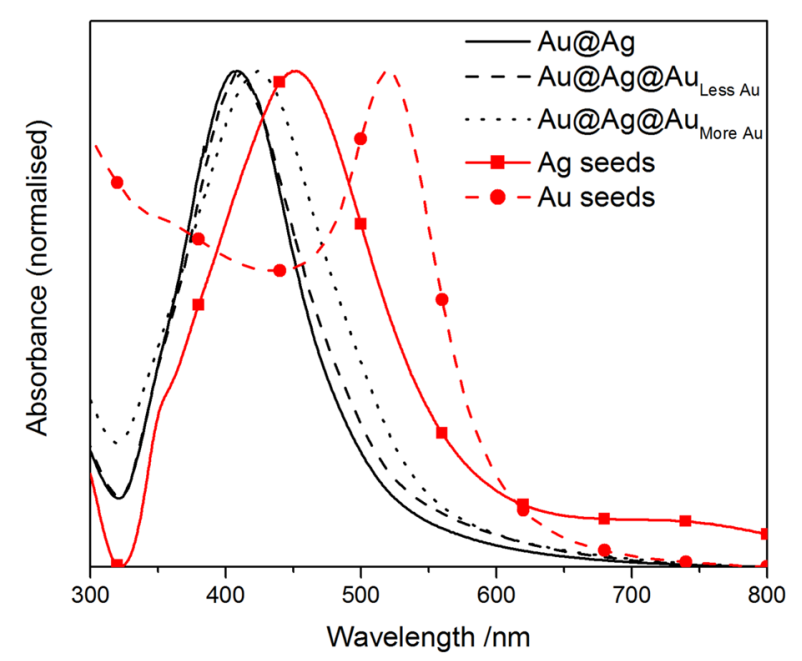

Figure 1. UV-visible spectra for the as-synthesized colloidal systems.

spectra. ${ }^{17,48}$ The silver character is evidently dominant over the gold character, and with the Au@Ag@Au additional gold has virtually no impact on the LSPR compared to the Au@Ag system, in agreement with previous reports. ${ }^{17}$ The absorption for the Au@Ag@Au_More Au colloid shows redshift compared to the $\mathrm{Au} @ \mathrm{Ag} @_{\text {Au_Less Au }}$ colloid. This is attributable to an increase in gold character; while redshift of the LSPR can also be caused by an increase in particle size, ${ }^{49}$ since the TEM data shows a ca. $5 \mathrm{~nm}$ decrease in the diameter of the Au@Ag@Au $\mathrm{Au}$ Less Au sample (see Figure 2), the observed redshift must be a result of the difference in composition. ${ }^{15,50}$ The LSPR peak for these systems does not lie between the LSPR peaks of monometallic silver and gold on the above plot (as would be expected with silver, gold, and bimetallic nanoparticles of comparable size ${ }^{51}$ ) as the large size of the silver nanoparticles (diameter $77 \mathrm{~nm}$ ) substantially redshifts the silver LSPR peak. To confirm the stability of the colloids, UV-vis spectra were recorded again, one month after synthesis; these spectra are shown in Figure S5 (Supporting Information).

TEM images and particle size distributions of the colloids are shown in Figure 2. The pure gold colloid has an average diameter of $13.1 \pm 0.1 \mathrm{~nm}$, with a standard deviation of $2.2 \mathrm{~nm}$. The pure silver colloid was substantially anisotropic and polydisperse, consisting of both quasi-spherical particles and rods. The Au@Ag colloid contains quasi-spherical particles with an average diameter of $26.8 \pm 0.4 \mathrm{~nm}$ and a standard deviation of 5.6 nm. Both Au@Ag@Au systems comprise quasi-spherical

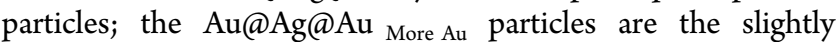
smaller system, with a mean diameter of $31.4 \pm 0.4 \mathrm{~nm}$ (standard deviation: $7.2 \mathrm{~nm}$ ), compared to $37.2 \pm 0.5 \mathrm{~nm}$ (standard deviation:9.0 nm) for the Au@Ag@Au Less Au particles. This counterintuitive result suggests the occurrence of the galvanic replacement reaction during the deposition of the gold outer shell. In this case the colloid that had been exposed to the most gold precursor would shrink in size. ${ }^{52}$ Given the thickness of the silver layer in these samples (ca. 6.9 $\mathrm{nm}$ ), this observation corroborates previous reports that the electron donation stabilizing effect is only effective over a short distance. $^{53}$

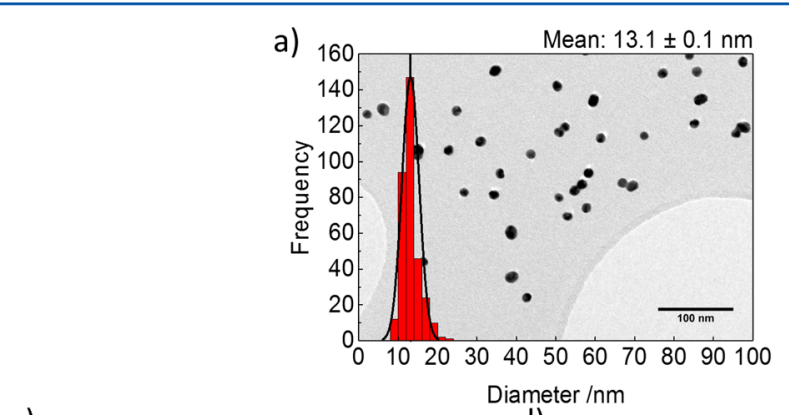

c)

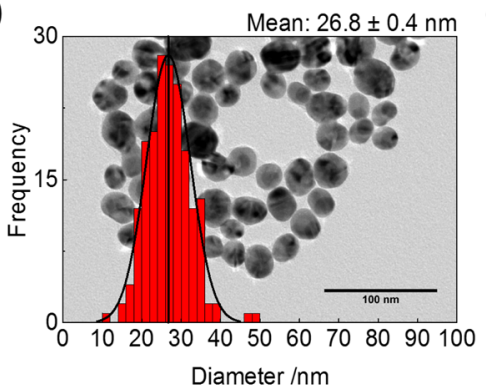

d)

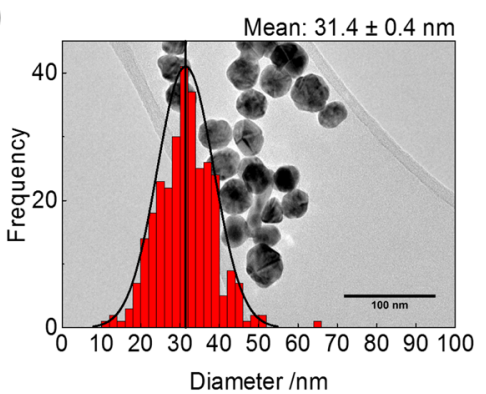

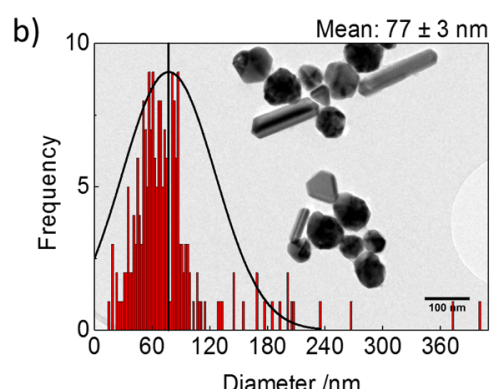

e)

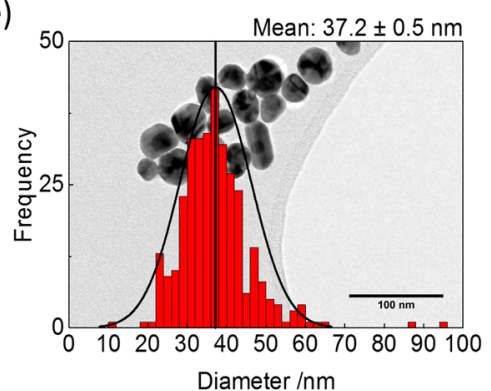

Figure 2. TEM images and particle size distribution histograms and Gaussians for (a) gold, (b) silver, (c) Au@Ag, (d) Au@Ag@Au_More Aw and (e) $\mathrm{Au} @ \mathrm{Ag} @ A u_{\text {Less Au }}$ colloids. The error quoted is the standard error of the mean. 
To further investigate the composition of the cores and shells, the size distribution of the cores observed in the micrographs of the Au@Ag@Au Less Au sample was measured and compared to the size distribution of the gold seed particles; the aim of this exercise was to determine whether the visible core is a pure gold seed or whether it includes silver. A comparison of the gold seed and core size distributions is shown in Figure 3; given the overlap of the curves, it is

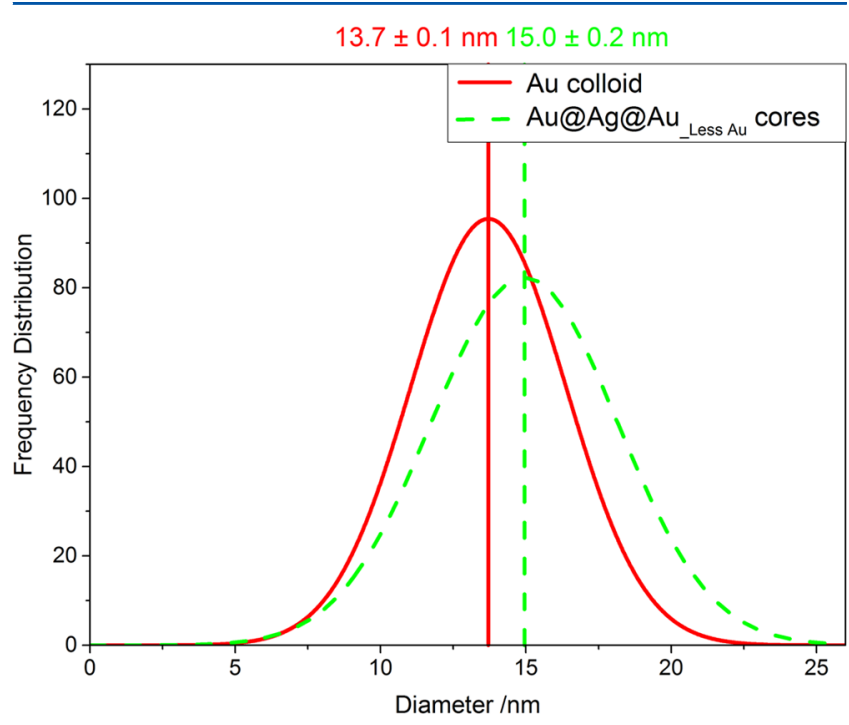

Figure 3. Overlay of particle size distribution curves (Gaussian) for gold seed particles and gold cores in the Au@Ag@Au_Less Au colloid, as determined by TEM analysis. The quoted uncertainty is the standard error of the mean.

reasonable to say that the sizes of the cores and the gold seed particles can be considered the same. This suggests that the core is pure gold.

There is no evidence in the TEM images for the formation of porous/spongy silver or hollow nanostructures, as are sometimes observed during the preparation of bimetallic nanoparticles. $^{54}$

Au L3 edge XANES data are shown in Figure 4 (standards inset). It is clear that the samples are in the metallic state, without any chloride or oxidic components. Furthermore, there are noticeable differences, in the XANES data, between the $\mathrm{Au}-\mathrm{Ag}$ colloids and the pure nanoparticles/Au foil, in particular in the region between 11920 and $11940 \mathrm{eV}$. These are very similar to those reported by Maenosono et al. ${ }^{29}$ These differences were interpreted as a consequence of electron transfer between $\mathrm{Au}$ and $\mathrm{Ag}$ orbitals. Therefore, we used this difference in the XANES at the Au L3 edge to confirm the existence of an $\mathrm{Au} / \mathrm{Ag}$ interface, as opposed to simply separate $\mathrm{Au}$ and $\mathrm{Ag}$ particles. ${ }^{55}$

Similarly, we also examined the Ag K-edge XANES (Figure 5); this confirms that $\mathrm{Ag}$ is present in metallic form and there is no evidence for any oxide, chloride, or nitrate salts being present in the colloids.

In order to determine the nature of this interaction (i.e., interfacial or alloying) and to extract the structure of the particles, we analyzed the EXAFS data of the samples. We analyzed both the Au L3- and Ag K-edges simultaneously, using procedures described elsewhere. ${ }^{28,56}$

Fourier transforms for the Au@Ag and Au@Ag@Au colloids, along with the best fits and selected TEM images, are shown in

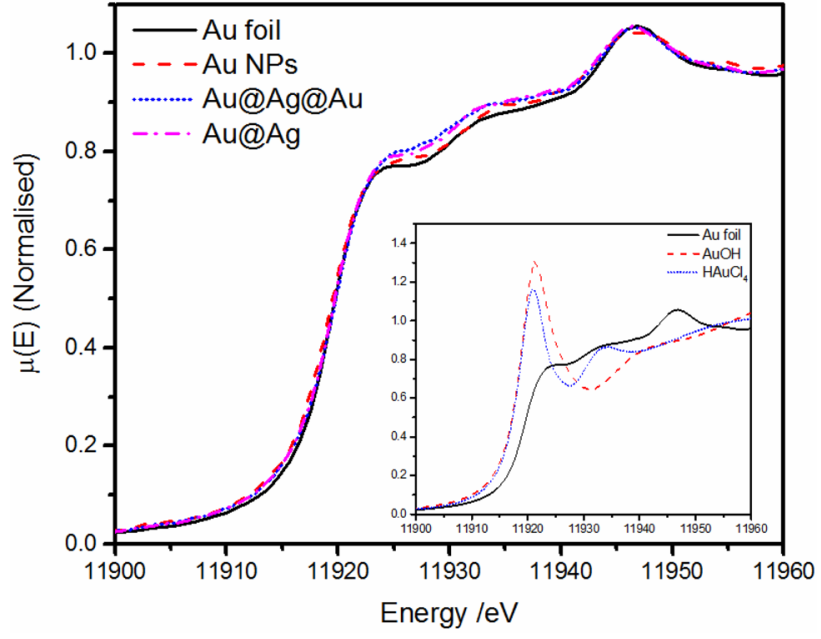

Figure 4. Au L3-edge XANES for bimetallic Au/Ag colloids (main figure) and standards (inset). Smoothed by performing a boxcar average (width $3 \mathrm{eV}$ ).

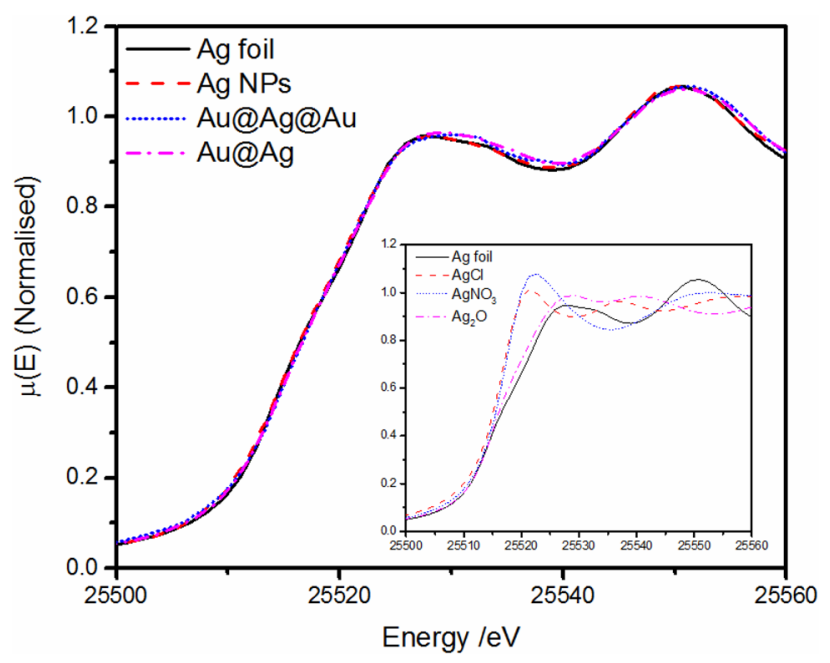

Figure 5. Ag K-edge XANES for bimetallic $\mathrm{Au} / \mathrm{Ag}$ colloids (main figure) and standards (inset). Smoothed by performing a boxcar average (width $3 \mathrm{eV}$ ).

Figure 6, and the EXAFS are shown in Figure S6 (Supporting Information). The structural parameters for these fits are given in Table 1. The EXAFS fitting procedure was performed at both edges simultaneously, to obtain a single model for the system. Determination of whether the particles are segregated or the degree of alloying present was then made by comparing the fitted coordination number to the composition, similarly to previously published work. ${ }^{19,31}$

Analysis of the EXAFS fitting parameters for the $\mathrm{Au} @ \mathrm{Ag}$ system shows a dominant contribution from monometallic paths at both edges $(\mathrm{Au}-\mathrm{Au}, \mathrm{Ag}-\mathrm{Ag}$ both have a coordination number of $\sim 12$ ), indicating that the particles are segregated. The gold L3 edge EXAFS data, here, is particularly compelling since gold is the minority component in the system, and, therefore, alloying would appear most prominently at the gold $\mathrm{L} 3$ edge. However, when the $\mathrm{Au}-\mathrm{Ag}$ and $\mathrm{Ag}-\mathrm{Au}$ scattering paths are excluded from the fit, the R-factor rises from 0.014 to 0.026 (Figure S7 and Table S2, Supporting Information), and this indicates that the contribution from the $\mathrm{Au}-\mathrm{Ag} / \mathrm{Ag}-\mathrm{Au}$ paths, although very small, is real. Therefore, the presence of a 
a)

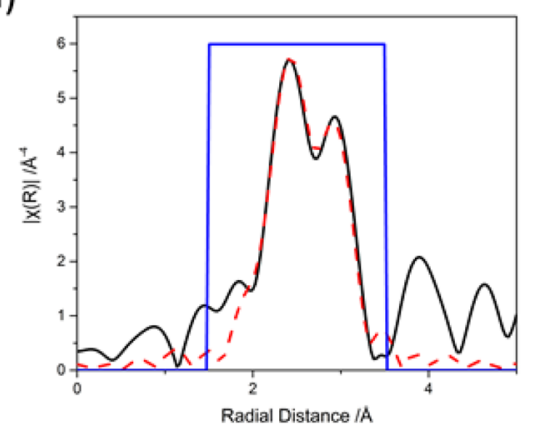

d)

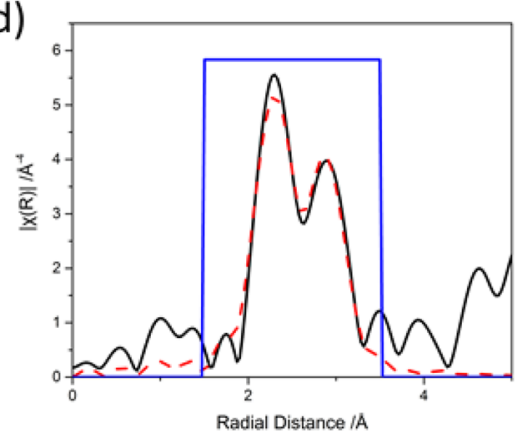

b)

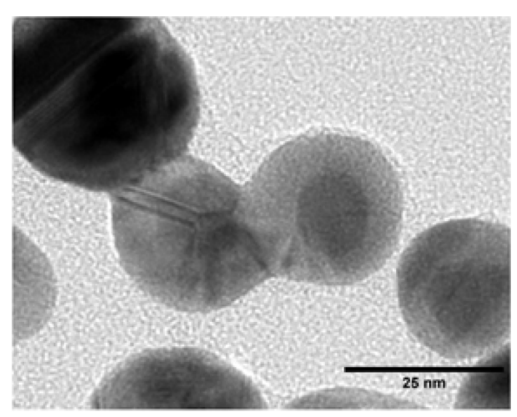

e)

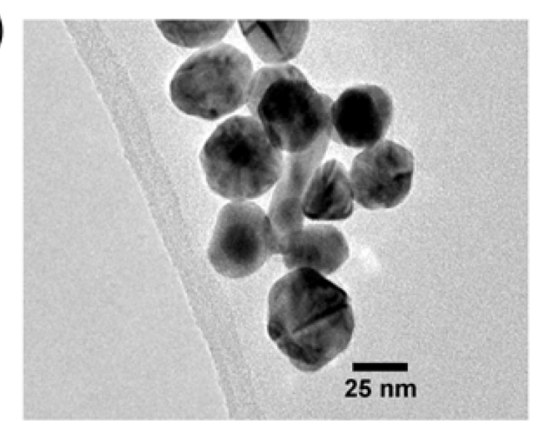

c)

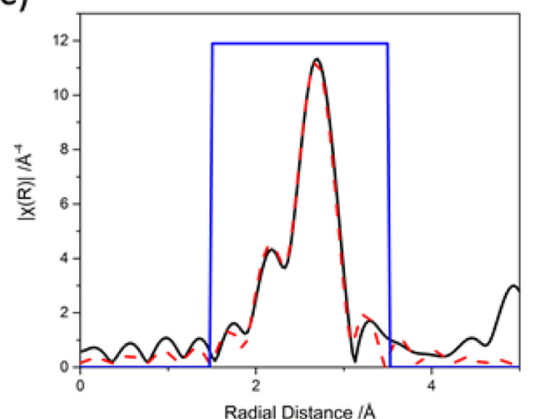

f)

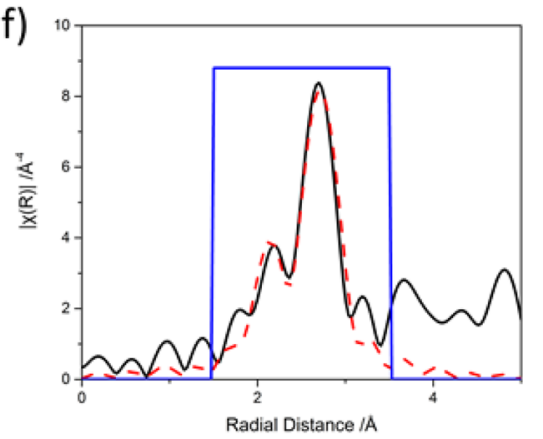

Figure 6. Fourier transforms of EXAFS data (solid black curves) and fits (red dashed curves) for (a) Au@Ag colloid Au L3-edge, (b) Au@Ag colloid TEM image, (c) Au@Ag colloid Ag K-edge, (d)Au@Ag@Au colloid Au L3-edge, (e)Au@Ag@Au colloid TEM image, and (f) Au@Ag@Au colloid Ag K-edge. The blue box represents the R-space fitting window.

Table 1. Fitting Parameters Used to Model EXAFS Data for the Bimetallic Systems ${ }^{a}$

\begin{tabular}{|c|c|c|c|c|c|c|c|}
\hline nominal structure & $x$ & edge & path & $\mathrm{CN}$ & $\sigma^{2}$ & $R(\AA)$ & $R$ factor \\
\hline \multirow[t]{4}{*}{ Au@Ag } & \multirow[t]{4}{*}{$0.13(\mathrm{SD}=0.06)$} & \multirow[t]{2}{*}{$\mathrm{Au}$} & $\mathrm{Au}-\mathrm{Au}$ & $12(2)$ & $0.010(2)$ & $2.87(1)$ & \multirow[t]{4}{*}{0.014} \\
\hline & & & $\mathrm{Au}-\mathrm{Ag}$ & $0.9(6)$ & $0.003(3)$ & $2.88(3)$ & \\
\hline & & \multirow[t]{2}{*}{$\mathrm{Ag}$} & $\mathrm{Ag}-\mathrm{Ag}$ & $12(2)$ & $0.011(2)$ & $2.87(1)$ & \\
\hline & & & $\mathrm{Ag}-\mathrm{Au}$ & $0(1)$ & $0.003(3)$ & $2.88(3)$ & \\
\hline \multirow[t]{4}{*}{ Au@Ag@Au } & \multirow[t]{4}{*}{$0.26(\mathrm{SD}=0.01)$} & \multirow[t]{2}{*}{$\mathrm{Au}$} & $\mathrm{Au}-\mathrm{Au}$ & $9(2)$ & $0.008(2)$ & $2.85(1)$ & \multirow[t]{4}{*}{0.029} \\
\hline & & & $\mathrm{Au}-\mathrm{Ag}$ & $2.0(7)$ & $0.004(2)$ & $2.84(2)$ & \\
\hline & & \multirow[t]{2}{*}{$\mathrm{Ag}$} & $\mathrm{Ag}-\mathrm{Ag}$ & $9(2)$ & $0.011(2)$ & $2.85(2)$ & \\
\hline & & & $\mathrm{Ag}-\mathrm{Au}$ & $2(2)$ & $0.004(2)$ & $2.84(2)$ & \\
\hline
\end{tabular}

$a_{x}$ is the mole fraction of $\mathrm{Au}, \sigma^{2}$ is the EXAFS Debye-Waller factor, $R$ is the fitted half path length, and $\mathrm{CN}$ is the coordination number. Uncertainty in the final digit is given in parentheses after the value. All values have been rounded as appropriate given their uncertainty. Compositional data is taken from EDS measurements; EDS spectra and maps, and further discussion, are shown in Figures S8-S13 (Supporting Information). SD is the standard deviation of the compositional data.

small contribution from the bimetallic paths can be assigned to the interaction between the two metals at the interface between the gold core and the silver shell. Previous reports have suggested that it is possible that limited alloying has occurred in the interfacial region; ${ }^{19}$ however, this would be expected to increase the $\mathrm{Au}-\mathrm{Ag} / \mathrm{Ag}-\mathrm{Au}$ scattering path contributions.

The structural parameters for the $\mathrm{Au} @ \mathrm{Ag} @ \mathrm{Au}$ system (Table 1) show dominant single element paths at both $\mathrm{Au}$ L3 and Ag K-edges; however, at both edges, there is a greater contribution from the bimetallic paths than displayed by the $\mathrm{Au} @$ Ag system. At the Ag K-edge, this can be explained by the existence of the second gold-silver interface present in a goldsilver-gold structure; however, the doubling of the mole fraction of gold in the system would overcome this at the gold edge, reducing the contribution from bimetallic paths, if there were a pure gold outer shell. Instead, the contribution from bimetallic paths is also increased at the gold edge. The most reasonable explanation for this is that the silver shell (ca. 6.9 $\mathrm{nm}$ ) extends beyond the short distance (ca. $1 \mathrm{~nm}$ ) that the electron donation effect is known to protect it for, ${ }^{53}$ leading to galvanic replacement and alloying in the shell. In summary, this suggests that the Au@Ag@Au particles form a gold core surrounded by an alloy shell-whether this alloy shell is homogeneous or possesses a composition gradient is unclear.

Excluding the bimetallic paths from the Au@Ag@Au fit resulted in increased uncertainty in the fitting parameters and increased R-factor (from 0.029 to 0.082; Figure S7 and Table S2, Supporting Information), demonstrating that inclusion of the bimetallic paths improved the fit. Nevertheless, the ability to achieve a rough fit without the bimetallic paths demonstrates the presence of segregation (arising from the gold core) in this system too.

These results are consistent with the TEM images shown in Figure 6b,e (and also in Figures S14-S16 Supporting Information), where core@shell structures are clearly visible in both the $\mathrm{Au} @ \mathrm{Ag}$ and $\mathrm{Au} @ \mathrm{Ag} @ A u \_$More Au particles. For $\mathrm{Au} @ A g @ A u \_$More Aw despite the ideal double shell structure, 
only one shell is visible in the image, supporting the structural assignment of Au@alloy made from the EXAFS analysis.

\section{CONCLUSIONS}

The data presented here provide insight into the structures of bimetallic gold and silver colloidal nanoparticles. The particles with a nominal structure of $\mathrm{Au} @ \mathrm{Ag}$ were found to contain only an almost indistinguishable amount of alloying, attributable to the interface, while those with a nominal structure of Au@Ag@ Au were found to display partial alloying in the outer shell; this was due to the thickness of the silver shell exceeding the distance over which the electron donation effect can stabilize the silver, giving an actual structure of Au@Au/Ag-alloy. From the evidence for $\mathrm{Au}-\mathrm{Ag}$ interactions in the $\mathrm{Au} \mathrm{L} 3$ edge XANES, it was possible to confirm that the presence of bimetallic particles, rather than two species of monometallic particles. For both these samples results obtained from $\mathrm{Au} \mathrm{L}_{3}$ and Ag $\mathrm{K}$ edge EXAFS and transmission electron microscopy were found to be consistent.

\section{ASSOCIATED CONTENT}

\section{S Supporting Information}

The Supporting Information is available free of charge on the ACS Publications website at DOI: 10.1021/acs.jpcc.6b11186.

Simulated $\mathrm{Au}$ and $\mathrm{Ag}$ PXRD patterns (Figure S1); Experimental setup (Figure S2); Further details of EXAFS fitting procedure and EXAFS and Fourier transforms of gold and silver colloids fitted to both monometallic (Figure S3) and bimetallic models (Figure S4) and parameters for these fits (Table S1); UV-vis spectra showing stability of colloids over 1 month period (Figure S5); EXAFS of bimetallic colloids (Figure S6); Fourier transforms of rejected fitting models (monometallic paths only (Figure S7 and Table S2)); EDS data and analysis (Figures S8-S13); HRTEM image of a core@shell particle (Figure S14); and line profiles at various points on its surface (Figures S15 and S16). (PDF)

\section{AUTHOR INFORMATION}

\section{Corresponding Authors}

*E-mail: shinya@jaist.ac.jp.

*E-mail: g.sankar@ucl.ac.uk.

ORCID

Ian J. Godfrey: 0000-0002-9195-1332

Shinya Maenosono: 0000-0003-2669-8219

Gopinathan Sankar: 0000-0001-5152-3424

\section{Author Contributions}

The manuscript was written through contributions of all authors. All authors have given approval to the final version of the manuscript.

\section{Funding}

EPSRC grant: EP/L015862/1

\section{Notes}

The authors declare no competing financial interest.

\section{ACKNOWLEDGMENTS}

We thank Diamond Light Source and the European Synchrotron Radiation Facility for provision of beam time (B18 proposal \# SP9949 and BM23 proposal \# CH3955). EDS mapping and some TEM measurements were carried out at the
UK Catalysis Hub at Research Complex at Harwell (RCaH) and $\mathrm{W}$. Jones $(\mathrm{RCaH})$ is thanked for assistance with these. UCL, JAIST, EPSRC and JASSO are thanked for providing studentship funding through the M3S IDC at UCL (grant EP/ L015862/1).

\section{ABBREVIATIONS}

$\sigma^{2}$, EXAFS Debye-Waller factor; CN, coordination number; $\mathrm{R}$, half-path length; SD, standard deviation

\section{REFERENCES}

(1) Haruta, M. When Gold Is Not Noble: Catalysis by Nanoparticles. Chem. Rec. 2003, 3, 75-87.

(2) Hashmi, A. S. K.; Hutchings, G. J. Gold Catalysis. Angew. Chem., Int. Ed. 2006, 45, 7896-7936.

(3) Hashmi, A. S. K.; Hutchings, G. J. Gold Catalysis - the Journey Continues. Catal. Sci. Technol. 2013, 3, 2861.

(4) Villa, A.; Dimitratos, N.; Chan-Thaw, C. E.; Hammond, C.; Prati, L.; Hutchings, G. J. Glycerol Oxidation Using Gold-Containing Catalysts. Acc. Chem. Res. 2015, 48, 1403-1412.

(5) Santos, K. de O.; Elias, W. C.; Signori, A. M.; Giacomelli, F. C.; Yang, H.; Domingos, J. B. Synthesis and Catalytic Properties of Silver Nanoparticle-Linear Polyethylene Imine Colloidal Systems. J. Phys. Chem. C 2012, 116, 4594-4604.

(6) Salehi-Khojin, A.; Jhong, H.-R. M.; Rosen, B. A.; Zhu, W.; Ma, S.; Kenis, P. J. A.; Masel, R. I. Nanoparticle Silver Catalysts That Show Enhanced Activity for Carbon Dioxide Electrolysis. J. Phys. Chem. C 2013, 117, 1627-1632.

(7) Schwank, J. Gold in Bimetallic Catalysts. Gold Bull. 1985, 18, 210.

(8) Kennedy, J.; Jones, W.; Morgan, D. J.; Bowker, M.; Lu, L.; Kiely, C. J.; Wells, P. P.; Dimitratos, N. Photocatalytic Hydrogen Production by Reforming of Methanol Using $\mathrm{Au} / \mathrm{TiO}_{2}, \mathrm{Ag} / \mathrm{TiO}_{2}$ and $\mathrm{Au}-\mathrm{Ag} /$ $\mathrm{TiO}_{2}$ Catalysts. Catal. Struct. React. 2015, 1, 35-43.

(9) Villa, A.; Wang, D.; Su, D. S.; Prati, L. New Challenges in Gold Catalysis: Bimetallic Systems. Catal. Sci. Technol. 2015, 5, 55-68.

(10) Wang, D.; Villa, A.; Porta, F.; Prati, L.; Su, D. Bimetallic Gold/ Palladium Catalysts: Correlation Between Nanostructure and Synergistic Effects. J. Phys. Chem. C 2008, 112, 8617-8622.

(11) Lopez-Sanchez, J. A.; Dimitratos, N.; Hammond, C.; Brett, G. L.; Kesavan, L.; White, S.; Miedziak, P.; Tiruvalam, R.; Jenkins, R. L.; Carley, A. F.; et al. Facile Removal of Stabilizer-Ligands from Supported Gold Nanoparticles. Nat. Chem. 2011, 3, 551-556.

(12) Kilmartin, J.; Sarip, R.; Grau-Crespo, R.; Di Tommaso, D.; Hogarth, G.; Prestipino, C.; Sankar, G. Following the Creation of Active Gold Nanocatalysts from Phosphine-Stabilized Molecular Clusters. ACS Catal. 2012, 2, 957-963.

(13) Pozun, Z. D.; Rodenbusch, S. E.; Keller, E.; Tran, K.; Tang, W.; Stevenson, K. J.; Henkelman, G. A Systematic Investigation of $P$ -Nitrophenol Reduction by Bimetallic Dendrimer Encapsulated Nanoparticles. J. Phys. Chem. C 2013, 117, 7598-7604.

(14) Kästner, C.; Thünemann, A. F. Catalytic Reduction of 4Nitrophenol Using Silver Nanoparticles with Adjustable Activity. Langmuir 2016, 32, 7383-7391.

(15) Mott, D.; Lee, J.; Thuy, N. T. B.; Aoki, Y.; Singh, P.; Maenosono, S. A Study on the Plasmonic Properties of Silver Core Gold Shell Nanoparticles: Optical Assessment of the Particle Structure. Jpn. J. Appl. Phys. 2011, 50, 65004.

(16) Mott, D. M.; Anh, D. T. N.; Singh, P.; Shankar, C.; Maenosono, S. Electronic Transfer as a Route to Increase the Chemical Stability in Gold and Silver Core-shell Nanoparticles. Adv. Colloid Interface Sci. 2012, 185-186, 14-33.

(17) Anh, D. T. N.; Singh, P.; Shankar, C.; Mott, D.; Maenosono, S. Charge-Transfer-Induced Suppression of Galvanic Replacement and Synthesis of (Au@Ag)@Au Double Shell Nanoparticles for Highly Uniform, Robust and Sensitive Bioprobes. Appl. Phys. Lett. 2011, 99, 73107. 
(18) Deng, L.; Hu, W.; Deng, H.; Xiao, S.; Tang, J. Au-Ag Bimetallic Nanoparticles: Surface Segregation and Atomic-Scale Structure. J. Phys. Chem. C 2011, 115, 11355-11363.

(19) Shibata, T.; Bunker, B. A.; Zhang, Z.; Meisel, D.; Vardeman, C. F.; Gezelter, J. D. Size-Dependent Spontaneous Alloying of Au-Ag Nanoparticles. J. Am. Chem. Soc. 2002, 124, 11989-11996.

(20) Swanson, H. E.; Tatge, E. Standard X-Ray Diffraction Powder Patterns. Vol. I, Data for 54 Inorganic Substances; National Bureau of Standards circular539, v. 1; National Bureau of Standards: Washington, DC, 1953.

(21) Van der Heide, P. X-Ray Photoelectron Spectroscopy: An Introduction to Principles and Practices; Wiley: Hoboken, NJ, 2012.

(22) Koningsberger, D. C.; Mojet, B. L.; van Dorssen, G. E.; Ramaker, D. E. XAFS Spectroscopy; Fundamental Principles and Data Analysis. Top. Catal. 2000, 10, 143-155.

(23) Russell, A. E.; Rose, A. X-Ray Absorption Spectroscopy of Low Temperature Fuel Cell Catalysts. Chem. Rev. 2004, 104, 4613-4636.

(24) McBreen, J.; Mukerjee, S. In Situ X-Ray Absorption Studies of a Pt-Ru Electrocatalyst. J. Electrochem. Soc. 1995, 142, 3399.

(25) Harada, M.; Ikegami, R. In Situ Quick X-Ray Absorption Fine Structure and Small-Angle X-Ray Scattering Study of Metal Nanoparticle Growth in Water-in-Oil Microemulsions during Photoreduction. Cryst. Growth Des. 2016, 16, 2860-2873.

(26) Stoupin, S.; Chung, E.-H.; Chattopadhyay, S.; Segre, C. U.; Smotkin, E. S. Pt and Ru X-Ray Absorption Spectroscopy of PtRu Anode Catalysts in Operating Direct Methanol Fuel Cells. J. Phys. Chem. B 2006, 110, 9932-9938.

(27) Wang, A.-Q.; Chang, C.-M.; Mou, C.-Y. Evolution of Catalytic Activity of $\mathrm{Au}-\mathrm{Ag}$ Bimetallic Nanoparticles on Mesoporous Support for CO Oxidation. J. Phys. Chem. B 2005, 109, 18860-18867.

(28) Ash, P. W.; Boyd, D. A.; Hyde, T. I.; Keating, J. L.; Randlshofer, G.; Rothenbacher, K.; Sankar, G.; Schauer, J. J.; Shafer, M. M.; Toner, B. M. Local Structure and Speciation of Platinum in Fresh and RoadAged North American Sourced Vehicle Emissions Catalysts: An X-Ray Absorption Spectroscopic Study. Environ. Sci. Technol. 2014, 48, $3658-3665$.

(29) Nishimura, S.; Dao, A. T. N.; Mott, D.; Ebitani, K.; Maenosono, S. X-Ray Absorption Near-Edge Structure and X-Ray Photoelectron Spectroscopy Studies of Interfacial Charge Transfer in Gold-SilverGold Double-Shell Nanoparticles. J. Phys. Chem. C 2012, 116, 45114516.

(30) Mansour, A. N.; Cook, J. W.; Sayers, D. E. Quantitative Technique for the Determination of the Number of Unoccupied DElectron States in a Platinum Catalyst Using the L2,3 X-Ray Absorption Edge Spectra. J. Phys. Chem. 1984, 88, 2330-2334.

(31) Frenkel, A.; Machavariani, V.; Rubshtein, A.; Rosenberg, Y.; Voronel, A.; Stern, E. Local Structure of Disordered $\mathrm{Au}-\mathrm{Cu}$ and $\mathrm{Au}-\mathrm{Ag}$ Alloys. Phys. Rev. B: Condens. Matter Mater. Phys. 2000, 62, 93649371.

(32) Yen, C.-W.; Lin, M.-L.; Wang, A.; Chen, S.-A.; Chen, J.-M.; Mou, C.-Y. CO Oxidation Catalyzed by $\mathrm{Au}-\mathrm{Ag}$ Bimetallic Nanoparticles Supported in Mesoporous Silica. J. Phys. Chem. C 2009, 113, 17831-17839.

(33) Hauser, E. A.; Lynn, J. E. Experiments in Colloid Chemistry, 1st ed.; McGraw-Hill Book Co.: New York, 1940.

(34) Turkevich, J.; Stevenson, P. C.; Hillier, J. A Study of the Nucleation and Growth Processes in the Synthesis of Colloidal Gold. Discuss. Faraday Soc. 1951, 11, 55-75.

(35) Frens, G. Controlled Nucleation for the Regulation of the Particle Size in Monodisperse Gold Suspensions. Nature, Phys. Sci. 1973, 241, 20-22.

(36) Garcia, A. G.; Lopes, P. P.; Gomes, J. F.; Pires, C.; Ferreira, E. B.; Lucena, R. G. M.; Gasparotto, L. H. S.; Tremiliosi-Filho, G. EcoFriendly Synthesis of Bimetallic AuAg Nanoparticles. New J. Chem. 2014, 38, 2865.

(37) Yao, T.; Sun, Z.; Li, Y.; Pan, Z.; Wei, H.; Xie, Y.; Nomura, M.; Niwa, Y.; Yan, W.; Wu, Z.; et al. Insights Into Initial Kinetic Nucleation of Gold Nanocrystals. J. Am. Chem. Soc. 2010, 132, 76967701.
(38) Chen, H. M.; Liu, R. S.; Jang, L.-Y.; Lee, J.-F.; Hu, S. F. Characterization of Core-shell Type and Alloy $\mathrm{Ag} / \mathrm{Au}$ Bimetallic Clusters by Using Extended X-Ray Absorption Fine Structure Spectroscopy. Chem. Phys. Lett. 2006, 421, 118-123.

(39) Ojea-Jiménez, I.; Bastús, N. G.; Puntes, V. Influence of the Sequence of the Reagents Addition in the Citrate-Mediated Synthesis of Gold Nanoparticles. J. Phys. Chem. C 2011, 115, 15752-15757.

(40) Lee, P. C.; Meisel, D. Adsorption and Surface-Enhanced Raman of Dyes on Silver and Gold Sols. J. Phys. Chem. 1982, 86, 3391-3395.

(41) Schneider, C. A.; Rasband, W. S.; Eliceiri, K. W. NIH Image to ImageJ: 25 Years of Image Analysis. Nat. Methods 2012, 9, 671-675.

(42) Filipponi, A.; Borowski, M.; Bowron, D. T.; Ansell, S.; Di Cicco, A.; De Panfilis, S.; Itiè, J.-P. An Experimental Station for Advanced Research on Condensed Matter Under Extreme Conditions at the European Synchrotron Radiation Facility - BM29 Beamline. Rev. Sci. Instrum. 2000, 71, 2422.

(43) Mathon, O. Upgrade Of BM29 and ID24 Optics. Two Complementary Beamlines For XAS Measurements At ESRF. In AIP Conference Proceedings; AIP: San Francisco, CA, 2004; Vol. 705, pp 498-501.

(44) Dent, A. J.; Cibin, G.; Ramos, S.; Smith, A. D.; Scott, S. M.; Varandas, L.; Pearson, M. R.; Krumpa, N. A.; Jones, C. P.; Robbins, P. E. B18: A Core XAS Spectroscopy Beamline for Diamond. In Journal of Physics: Conference Series; Institute of Physics: Camerino, Italy, 2009; Vol. 190, p 12039.

(45) Sankar, G.; Bras, W. Insights Into the Formation of Microporous Materials by in Situ X-Ray Scattering Techniques. Catal. Today 2009, 145, 195-203.

(46) Ravel, B.; Newville, M. ATHENA, ARTEMIS, HEPHAESTUS: Data Analysis for X-Ray Absorption Spectroscopy Using IFEFFIT. J. Synchrotron Radiat. 2005, 12, 537-541.

(47) Klementev, K. V. Package "VIPER (Visual Processing in EXAFS Researches) for Windows. Nucl. Instrum. Methods Phys. Res., Sect. A 2000, 448, 299-301.

(48) Uppal, M. A.; Ewing, M. B.; Parkin, I. P. One-Pot Synthesis of Core-Shell Silver-Gold Nanoparticle Solutions and Their Interaction with Methylene Blue Dye. Eur. J. Inorg. Chem. 2011, 2011, 4534-4544.

(49) Haiss, W.; Thanh, N. T. K.; Aveyard, J.; Fernig, D. G. Determination of Size and Concentration of Gold Nanoparticles from UV-Vis Spectra. Anal. Chem. 2007, 79, 4215-4221.

(50) Zhu, J. Theoretical Study of the Optical Absorption Properties of Au-Ag Bimetallic Nanospheres. Phys. E 2005, 27, 296-301.

(51) Gomes, J. F.; Garcia, A. C.; Pires, C.; Ferreira, E. B.; Albuquerque, R. Q.; Tremiliosi-Filho, G.; Gasparotto, L. H. S. Impact of the AuAg NPs Composition on Their Structure and Properties: A Theoretical and Experimental Investigation. J. Phys. Chem. C 2014, 118, 28868-28875.

(52) Mott, D.; Thuy, N. T. B.; Aoki, Y.; Maenosono, S. Aqueous Synthesis and Characterization of $\mathrm{Ag}$ and $\mathrm{Ag}-\mathrm{Au}$ Nanoparticles: Addressing Challenges in Size, Monodispersity and Structure. Philos. Trans. R. Soc., A 2010, 368, 4275-4292.

(53) Shankar, C.; Dao, A. T. N.; Singh, P.; Higashimine, K.; Mott, D. M.; Maenosono, S. Chemical Stabilization of Gold Coated by Silver Core-shell Nanoparticles via Electron Transfer. Nanotechnology 2012, 23, 245704.

(54) Sun, Y.; Xia, Y. Mechanistic Study on the Replacement Reaction Between Silver Nanostructures and Chloroauric Acid in Aqueous Medium. J. Am. Chem. Soc. 2004, 126, 3892-3901.

(55) Tyson, C.; Bzowski, A.; Kristof, P.; Kuhn, M.; Sammynaiken, R.; Sham, T. Charge Redistribution in Au-Ag Alloys from a Local Perspective. Phys. Rev. B: Condens. Matter Mater. Phys. 1992, 45, 8924-8928.

(56) Hyde, T. I.; Ash, P. W.; Boyd, D. A.; Randlshofer, G.; Rothenbacher, K.; Sankar, G. X-Ray Absorption Spectroscopic Studies of Platinum Speciation in Fresh and Road Aged Light-Duty Diesel Vehicle Emission Control Catalysts. Platinum Met. Rev. 2011, 55, 233-245. 